\title{
Reducing Poverty through Community Based Forest Management in Asia
}

\author{
Sango Mahanty*, Jane Gronow", Mike Nurse* and Yam Malla* \\ ${ }^{*}$ Regional Community Forestry Training Centre for Asia and the Pacific (RECOFTC), Bangkok, \\ Thailand \\ E-mail: ostm@ku.ac.th \\ \# Independent Consultant
}

\begin{abstract}
Recent years have seen a growing interest in the role and potential of community based forest management $(\mathrm{CBFM})^{1}$ as a vehicle for poverty reduction. Some analysts suggest that CBFM initiatives have limited potential for poverty reduction because they are prone to elite capture; focus on low value, degraded forests; emphasise forests rather than integrated NR based livelihood development; and because of the high transaction costs facing the poorest of the poor in harnessing high-value goods such as timber. This paper proposes that CBFM has the potential to help the poor cope with or even begin to move out of poverty, but this potential is as yet only partially realised. We examine the issues involved in promoting CBFM as a vehicle for poverty reduction and review selected pro-poor approaches to CBFM in the Asian region. We conclude that there are three key areas in which more work is needed by CBFM professionals in order to harness the poverty reduction potential of community forestry: governance, appropriate enterprise development and integrated approaches.
\end{abstract}

Keywords: poverty reduction, pro-poor, community based forest management, livelihoods, enterprise, governance

\section{INTRODUCTION}

The groundswell in community based forest management (CBFM) in Asia over the 1980s and 1990s has been paralleled by an interest in poverty reduction as well as sustainable resource management.

Since CBFM initiatives aim to strengthen the rights of communities to access and manage forests to improve livelihoods and resource conditions (WRI et al., 2005), the synergy between CBFM and poverty reduction should, in theory, be strong. The question remains, however, whether this translates into poverty reduction in practice, in particular for the most marginalized groups in rural society (Hobley, 2005). The current indications are that there are examples of CBFM contributing to poverty reduction, but that this is limited to a few cases and there is no evidence of "scaling up" (Gilmour et al., 2004).

This paper sets out to articulate the key concepts and challenges facing a pro-poor approach to $\mathrm{CBFM}$ and to provide an overview of some promising approaches that are starting to tackle these challenges. From our regional perspective at RECOFTC, we believe that the potential of CBFM is as yet only partially realised and a more effective poverty reduction approach can be achieved if these challenges can be faced and used to improve CBFM programs.

We start by examining and defining the concepts of poverty and marginalisation, considering in greater detail the relationship between poverty reduction and CBFM. We then consider the experiences of using CBFM for poverty reduction in Asia, drawing on selected case studies that are showing some promise in reaching the most marginalised groups. Finally, we bring together some challenges and potential directions for CBFM if it is to contribute more strongly to reducing poverty in the future. The case studies presented here are drawn from existing literature, which in

1 CBFM involves the governance and management of forest resources by communities, in collaboration with other stakeholders, for commercial purposes, subsistence, timber production, nontimber forest products, wildlife, conservation of biodiversity and environment, and for social and religious reasons. 
some cases was limited in the extent of data and detail provided. We therefore present these cases with an aim of providing an overview of potential approaches and strategies to stimulate discussion, experimentation and research, rather than to evaluate them or present them as a 'blueprint' for pro-poor CBFM.

\section{POVERTY AND COMMUNITY BASED FOREST MANAGEMENT}

\section{The Concept of Poverty}

The World Bank's widely accepted poverty benchmark of US\$1 per capita per day forces us to acknowledge that in 2001 there were 1.1 billion people in the world living in "extreme economic poverty" (www.worldbank.org/poverty). If US\$2 is used as the threshold, almost half of humankind (2.7 billion people) was living on less than US\$2 a day in $2001^{2}$. These are shocking statistics for the start of the 21 st century.

Measuring the number of people living in poverty gives an indication of scale, but tells us nothing about what it is like to be poor. Since the introduction of the Millennium Development Goals in 2000, national governments and international development agencies have tried to better understand the nature of poverty: why it is so pernicious and how best to mitigate or reduce it. The widely accepted World Bank definition below helps us to realize that to be poor is not just to lack material possessions, but to feel perpetually insecure and vulnerable to the slightest misfortune.

"Poverty is defined here as a pronounced deprivation of well-being related to lack of material income or consumption, low levels of education and health, vulnerability and exposure to risk, lack of opportunity to be heard and powerlessness. (World Bank 2002)."

How do the rural poor cope with poverty? Our understanding of, and respect for, the way in which the rural poor respond to the situation they find themselves has deepened in recent years. Poor households are inventive and resourceful: they constantly strive to combine whatever assets they can access in order to create a set of diverse livelihoods. Current development practice considers that livelihoods are made up of five types of assets: human (e.g. education), social and political (e.g. family and government connections), financial (e.g. access to credit), natural (e.g. forests) and physical (e.g. equipment, buildings, roads). The degree to which communities, families and individuals can access these five assets and put them to productive use determines their ability to build sustainable livelihoods (Carney, 1999).

Poverty reduction strategies fall into two groups: poverty mitigation aims to help the poor cope with poverty, and the more ambitious poverty elimination aims to alleviate poverty altogether. In each case, development agencies are increasingly committed to understanding the underlying dimensions of rural poverty and to tackling the barriers that keep people poor, such as inequitable access to resources. This in turn requires development agents to be more critical of their own interventions and the actual impact they have on marginalized groups.

It is self evident that in any society the resources available to different groups vary greatly. The 'middle class' and 'elite' levels of society generally expect to harness the opportunities provided by education, access to land, credit, government officials and health services to build a relatively secure future for their families. The vulnerability and powerlessness highlighted in the World Bank definition mean the marginalized are far less able to do so. Within poor rural communities the degree of vulnerability varies; one typology (Brocklesby, 2004; Wood and Salway, 2000; Loughhead et al., 2000) highlights the ways in which the

2 In the East Asia-Pacific and the South Asia regions the number of people living in extreme economic poverty in 2001 was significantly lower than in 1080 due to economic growth particularly in China.

${ }^{3}$ The "declining" poor possess very few assets, have no voice and may be near to destitution. They are unable to challenge local inequities or take advantage of development opportunities. The "coping" poor can meet their basic needs and have some assets. The "improving" poor have a range of assets and skills, are able to speak in solidarity with others and can take advantage of new opportunities (Hobley, 2005). 
capacity for action of the "declining" poor, the "coping" poor and the "improving" poor are different ${ }^{3}$.

What is the relationship between forests (and trees) and rural poverty? It is certainly well established that forests in rural areas of developing countries are culturally significant, are used for subsistence and commercial needs and provide important inputs to agriculture (Arnold, 2001). However our understanding of the role of forests in the lives of poor rural communities has moved on from a simple view, based on the supply of goods and services, to recognizing the strategic role that forests play in helping the poor cope with poverty. In addition to helping the poor meet household subsistence needs, they also fulfill important "safety net" functions in times of difficulty, enabling families to avoid destitution (Sunderlin et al., 2005). For example, berries that normally would not be collected can be important sources of nutrition in lean seasons. Non-timber forest products (NTFPs) sold in small quantities for low prices are generally regarded as an "employment of last resort," but can be a critical source of cash for school fees or agricultural inputs in the absence of savings or credit. Unfortunately, the factors that make NTFPs valuable "safety nets" limit their scope to lift people out of poverty ${ }^{4}$.

We know too that the poor also tend to be heavily dependent on common pool resources. If access to CPRs is suddenly restricted or denied, it can significantly increase the vulnerability of the poor. For instance, if a harvesting permit is given to an outsider, or a forest compartment to a plantation development company, or if forest fires are allowed to rage uncontrolled, the poor are often the hardest hit. The lack of voice we mentioned earlier ensures that their response to these scenarios often goes unnoticed: migration to other areas, increased indebtedness, declining health and strength, and children taken out of school.

Poverty elimination refers to the use of forest resources to help lift a household out of

4 "Safety net" NTFPs such as firewood, are often easily available to everyone and low in value; factors that in turn ensure they cannot command a high market price. poverty by acting as a source of savings, investment, capital accumulation, asset building and lasting improvements in income and well being (Sunderlin et al., 2005). In practice, the poor are often restricted to using forest and tree resources only to help mitigate poverty while the local elites and outsiders are able to harness the same resources, either legitimately or illegally, in order to accumulate wealth. While elites in a society can often dictate or influence the way natural resources are managed, the poor are often left only to respond to situations devised by and for others. This lack of control and attendant insecurity can make it almost impossible for the poor to plan, invest or improve their situation through forestry.

These and other factors help explain why the general contribution of forestry to poverty reduction has been so limited to date. Beck and Nesmith (2001:2) call for "an alternative paradigm and reconceptualization of poverty-environment relations, wherein the emphasis moves away from matters of resource supply to the questions of access, control and management". Once we take this on board, we soon see that there are a myriad of governance-related factors that skew the sector away from the interests of the poor. We use the term governance broadly here to refer to the processes, institutions or rules and norms, and practices through which we make decisions about resource management. This includes institutions and laws, participation rights and representation, what levels of authority are held at different scales, accountability and transparency, property rights and tenure, markets and financial flows, and how the system addresses risk and changing knowledge (UNDP et al., 2003).

A recent CIFOR study undertaken in Kalimantan concluded, "a good forest endowment allows people to live well at or near the subsistence leve... but opportunities to lift people out of poverty have been limited. But the future need not mirror the past." (Dewi et al., 2005: 13). How then do we begin to increase the contribution of forestry to poverty alleviation? In the recent publication, "Managing Ecosystems to Fight Poverty", four main strategies are identified to improve the poverty reduction potential of local ecosystems. These include: 
1. Strengthening resource management to ensure higher productivity and greater returns;

2. Improving governance so that the poor are empowered to "profit from nature";

3. Commercializing goods and services through marketing and enterprise development;

4. Developing mechanisms for payments for environmental services (WRI et al., 2005).

Pursuing any one of these strategies will involve removing institutional constraints, addressing the causes of poverty at different levels (local and beyond) and working at an appropriate scale in an integrated way, for example, by balancing and responding to the range of humanitarian and development assistance needs of the poorest (Fisher et al., 2005 and Bass et al., 2005).

\section{Tackling Poverty through CBFM}

Thus far we have only considered the relationship between forestry in general and poverty reduction; what about the CBFM context? Surely CBFM has had more success in addressing poverty than either the state or the private sector? In theory, a move from state to community tenure should remove some of the most significant barriers to pro-poor forestry: outsiders reaping the benefits and resource degradation through open access. All the evidence suggests that forest condition is indeed improved by shifting from a state to a community based tenure regime. However CBFM has had mixed results in addressing poverty amongst the poorest and most marginalized. This is to some extent understandable, given that CBFM has only recently started to shift its original emphasis on modalities for plantation and natural forest protection (i.e. environmental objectives) to deal also with poverty reduction, but the persistence of poverty in CBFM programs compels us to look in more detail at the challenges and issues.

User group systems can quickly mirror the social structures in which they develop. At the community level, access to the resources will often be determined by gender, age, social status and ethnicity. Community forests are just as prone to "capture" by local elites as any other valuable local resource. Ironically, open access scenarios may allow the poor easier access, albeit to a degraded resource. International development agencies have at times unwittingly exacerbated the problem by enthusiastically promoting new conservation regimes without paying sufficient attention to social heterogeneity in general and local power structures in particular.

Another weakness with CBFM is its focus to date on low value, degraded forests and its limited ability to reach into communities living in or near high value forests (Bhattacharya, 2006 and Poteete, 2004). If this trend continues, efforts may need to switch to other forms of participatory forestry tenure that provide less devolution of authority to communities (e.g. some forms of collaborative forest management) to ensure local people living adjacent to large scale productive forests will have access to the products come from such forests. For instance the Forest Management Units of Bhutan and Production Forests of Lao PDR can incorporate these forests, at least in a conditional way, into community livelihood strategies.

The emphasis on forests rather than integrated natural resource-based livelihood development has also been highlighted as a limitation of CBFM, since rural livelihoods are complex and poverty reduction is unlikely to be achieved with a focus on one dimension alone (Walker, 2005). Forests and trees are rarely the mainstay of rural households; the critical issue is the strategic role forest and tree resources play in helping families cope with poverty and moving out of poverty through more promising ventures such as agriculture and small enterprises.

Hobley (2005) summarises the situation well by explaining that while CBFM is potentially pro-poor, other types of forestry may also have a role in addressing poverty. As noted above, CBFM did not set out to be pro-poor; the early agendas had more to do with conservation and supply. As a result the capacity to benefit the poor has often been limited by assumptions of community homogeneity, over-promotion of indigenous systems without analysis of the social outcomes, avoidance of corruption issues, and lack of gender analysis. Just changing 
tenure regime does not in itself improve the lot of the poor, although combining this with strategies to engage the poor and address the causes of poverty can offer an important entry point for poverty reduction, as the examples below illustrate.

\section{APPROACHES TO PRO-POOR COMMUNITY FORESTRY IN ASIA: SELECTED CASES}

The preceding discussion highlighted three key areas in which CBFM needs to make progress if it is to improve its potential for reducing rural poverty: (a) enterprise based strategies, (b) governance related strategies, and (c) an integrated approach to poverty reduction based on an understanding of poverty and its causes (Hobley, 2005). Although CBFM is rarely pro-poor by design at the present time, the examples below highlight some potential directions and issues for pro-poor CBFM.

\section{Enterprise Based Strategies}

Many CBFM programs have focused on improving forest-based livelihoods through commercial use of forest resources. Research suggests that commercial markets for forest products offer a key avenue for overcoming poverty for many poor people in forested and marginal agricultural lands (Scherr et al., 2004). Some products and enterprise choices may offer greater potential than others; Scherr et al. highlight that the real income potential lies with forest commodities that have a large and growing national/international market, and/or niche products and services that offer high income earning potential for a limited number of producers. In terms of likely financial return, these are likely to outstrip products with high local demand but limited prospect for growth in the long term, or products for which demand falls as local incomes grow (for example, households may substitute fuelwood with kerosene as incomes increase) (Scherr et al., 2004).

Putting aside the level of return and financial viability of enterprises, however, our concern in this paper is how to ensure that benefits from enterprises translate to poverty reduction in the most marginalized groups. Experience to date is showing that reducing poverty in these groups requires particular attention to engaging these groups in appropriate ways, in addition to ensuring that the enterprise is sustainable in both environmental and economic terms. The institutional and design elements of enterprises can be crucial, as illustrated in these two examples from Nepal and Lao PDR.

\section{Pro-poor bel fruit juice in Nepal}

The following case study draws on the work of Dinesh Paudel (2005). The Tamakoshi Bel Juice Processing Company is a privatepublic partnership, including 10 Community Forest User Groups (CFUGs), 60 identified poor households from these 10 groups, and private investors. The social influence of caste is still high in these communities and those who are landless and of a low caste are typically identified as the poorest households. Gender equity also remains a key issue in both economic and political terms.

An understanding of the factors contributing to marginalization in participating communities has been essential to the development of a pro-poor approach, and has enabled poor households to be effectively targeted in the Bel juice enterprise:

1. The company's financial ownership structure fosters entrepreneurship amongst the poor. It includes three shareholder groups: 10 CFUGs $130 \%$ shares); 60 poor households identified from the 10 CFUGs (30\% of shares), 6 private entrepreneurs (40\% shares). By fostering entrepreneurship, the intension is to give poor households the ability to lift themselves out of poverty, as they get a dividend both directly and through the CFUG shareholding if the enterprise is profitable.

2. Poor households are employed on a partial to full-time basis in fruit collection and processing. Employees receive wages and may receive productivity bonuses.

3. While membership is on a household level, over $50 \%$ of the employees in the fruit collection and juice processing activities are women (this falls to just below 50\% when construction, management and transport activities are added). 
Analysis of employment and income data has shown an increase in the total wages of identified poor families, with the highest proportion of this income coming from enterprise related activities. As owners of the company, these families also reported experiencing enhanced social standing and a sense of dignity (Paudel, 2005).

\section{Bitter bamboo harvesting in Lao PDR}

The Nepal case contrasts with a more marketing/livelihoods focused example from Lao PDR, which also had positive impacts on poverty. The following case study draws on papers by Morris et al. (2004) and also NAFRI et al. (2005) about an IUCN and National Agriculture and Forestry Research Institute (NAFRI) supported project in Nam Pheng village in Oudomxay Province, Lao PDR.

Nam Pheng village had a very high proportion of poor households facing rice shortages for 4-6 months of the year (NAFRI et al., 2005). A major aim of the project was to support conservation by addressing poverty related factors that were driving overuse of NTFPs. This was facilitated through activities such as the establishment of a NTFP marketing group; introducing the use of weighing scales, enabling collectors to get a better return for their produce; and support for related activities, such as a rice bank to improve food security, water supply improvements and access to schooling.

Recent analyses of the project and its impacts have found that the number of "poor" households and households experiencing seasonal rice shortages has decreased in Nam Pheng village. Some critical factors that may have influenced income levels include: the marketing method; size of the area that a group has rights over; status and type of forest available; the richness of NTFPs and availability of labour within households to collect them; and weather conditions (NAFRI, 2005).

While the Bel Fruit Juice enterprise deliberately engaged the most marginalized groups, the bitter bamboo shoot project did not appear to target specific groups within the community, although perhaps the poorer groups were most likely to be involved with collecting and selling bitter bamboo shoots. One possible explanation for the success of two quite different enterprise approaches may be the considerable inequity in wealth and social status in the Nepal case, compared with the Lao PDR case, where a large proportion of the village was poor, and therefore even a non-targeted approach was able to improve the situation of the poor. If this is the case, then it may follow that the extent to which enterprise activities need to explicitly target the poor may depend upon the level of internal heterogeneity in a community. The Lao PDR case may also have targeted the poor through the choice of commodity, rather than in the governance of the enterprise as occurred in the Nepal case.

CBFM initiatives working with the broad definition of poverty proposed earlier are going beyond livelihoods related activities, to look also at governance related issues such as property rights and voice in policy and decision making processes.

\section{Addressing the Governance Context}

As noted previously, some of the fundamental governance issues influencing the poverty reduction potential of community based forest management include:

1. Secure resource access and management rights for the poor that are supported by appropriate policy and regulatory frameworks.

2. Decentralization of resource management in ways that benefit the poor, such as through policies that support the poor or encourage the involvement of marginalized groups in decision-making.

3. Rights to participation, information and justice. (WRI et al., 2005)

The two case studies below address these issues in various ways.

\section{Federating user groups and policy advocacy to improve returns from NTFP marketing in orissa, India}

This case study draws on discussions held in November 2005 with members of two NGOs: Vasundhara and the Regional Centre for Forestry and Governance (RCDC). Both of these organizations work with indigenous communities in Orissa to increase the benefits they receive from NTFP marketing. 
The state of Orissa has a history of community forest management, with community forests established in 19 districts and 8,000 villages across the state, although these community-managed forests are not recognized under formal Forest Department policy. Orissa has a relatively high proportion of indigenous people and NTFPs offer great poverty reduction potential here, given that a third of the population depends on NTFPs for their livelihoods - in some areas close to $100 \%$ of income is drawn from NTFPs. NTFPs are also an important revenue source for the government, however this disappears into central revenue rather than being invested into development activities in NTFP collecting communities.

A change in State government policy in 2002 enabled the handing over of around 68 NTFP products to management at the panchayat (local government) level. However, support for marketing is weak and the returns to the product collectors are reportedly low. Both Vasundhara and RCDC work on governance related issues as a means of improving NTFP based livelihoods.

Vasundhara is working to capture a greater proportion of revenue from NTFP sales by communities so that the revenue from NTFPs can be reinvested at the community level. Through a mix of enterprise and governance oriented strategies, such as the establishment of NTFP cooperatives and federations, they have supported collectors to obtain a better price for a number of products. Vasundhara also has an advocacy focus at the state and national level, where they aim to promote a consistent and fair policy on NTFP across neighbouring states, since the markets for these products span state boundaries.

RCDC, has facilitated multi-stakeholder platforms in the states of Orissa, Chattisgarh, Andhra and Madhya Pradesh to advocate for improvements in NTFPs policy, leading to a set of policy recommendations to state governments. A state level platform has also been formed to work on forestry issues with community representatives, NGOs, individual activists and researchers.

The approach of these organizations highlight that the solutions to poverty often lie beyond the local scale. In this case, a combination of enterprise development and policy advocacy is being used strategically to achieve long-term improvements to community livelihoods. Policy change, however, is a long-term process and the strategy of linking groups across localities through federations and multi-stakeholder platforms has been an important mechanism for strengthening the voices of marginalized groups in policy processes.

Governance related strategies in the Nepal Swiss Community Forestry Project

This case study draws on the experience of one of the authors (Nurse) who worked closely with the NSCFP for two years and an analysis of the poverty impacts of this project by Nurse et al., (2004). The project used a range of strategies to develop, pilot and test community forestry approaches that have led to specific pro-poor and positive environmental outcomes, some of which analyzed and addressed governance issues at the local and wider scales:

- Well-being ranking to identify the poorest households.

- Integrated development planning in focus groups (eg. women, poorest, elites) to identify development needs in forestry and other sectors (based on the finding that the poorest rarely need forestry interventions as a first priority).

- Coordination of government agencies and projects in delivering a range of products and services based on an integrated development plan.

- Governance coaching programs to improve the awareness and acceptance of community leaders for poverty reduction programs.

- Use of community forestry user group funds from the sale of products and fees to contribute to development activities such as goat raising, providing free forest products for the poorest, loans for medical costs or costs associated with life-cycle ceremonies (funerals, weddings) and scholarship programs.

- Devoting areas of community forestland to specific pro-poor activities, including fodder development. 
Nurse et al., (2004) found that to have a positive impact on poverty reduction, it is important for CBFM projects to positively discriminate for disadvantaged group members, such as in representation in Community Forest User Groups (CFUG) or supporting them in strengthening their access rights to resources. The representation of marginalized groups on decision making bodies has been supported by "governance coaching" processes to help user groups cope with social heterogeneity and enable representatives from marginal groups to have a voice in decision making processes.

The other critical issue broached in this project is the need to work for poverty reduction through "...a coordinated, integrated and flexible approach that works across compartmentalized project or government line agency boundaries..." (Nurse et al., 2004:55).

The Nepal and Indian examples highlight that the governance context can play a crucial role in determining the poverty impact of CBFM initiatives and that strategies to tackle governance issues can usefully form part of the mix of approaches to addressing poverty through CBFM. On the other hand, a policy and regulatory focus alone is seldom enough. Recent analysis of the functioning of Community Protected Areas in Cambodia has highlighted that while new by-laws have helped to secure the use and management rights of communities, the flow of benefits to the poorest were constrained by factors such as the facilitation skills of the staff that implements programs and the very high opportunity cost to the poor in participating in community based management (San, 2006). Even in the Philippines, where a strong enabling policy environment exists, effective implementation has been weakened by poor coordination and collaboration between national government, local government, civil society, and communities (Bacalla, 2006). It thus remains important to consider the implementation of pro-poor policy mechanisms and rules in addition to advocacy and policy change.
Targeting Poverty through an Integrated Approach with an Understanding of Marginalization Processes

As noted previously, community livelihoods and well-being rely more on forests; the poor do not think in compartments. An integrated approach that works across key resource linkages is therefore more likely to improve poverty reduction outcomes. This makes it important for CBFM programs to work from an understanding of the dimensions of poverty in a locality in order to recognize and support forestry's strategic role in addressing poverty. Through such an approach, the poverty mitigation role of forest resources can be strengthened, for example by supporting the poor to build savings from secure access to sustainably managed/harvested resources.

Unfortunately, CBFM, and indeed most development activities, have rarely proceeded on the basis of a deep understanding of the constraints faced by the poor in maintaining a secure livelihood and the strategies they employ in crisis. The risk then is that management regimes exclude the poor and other marginalized groups and are externally supported control by elites (Beck and Nesmith, 2001). The Nepal and Indian examples discussed previously have attempted to work with a more detailed understanding of this, but the further development of robust methodologies to develop such an understanding remains an important priority.

A focus on forests alone also carries the risk of emphasizing forest resource rights at the expense of other potential assets for the poor, such as agricultural land (Walker, 2004). The auther argues that this can trap the poor into forest dependency, rather than widening their range assets and livelihood options. The Nepal Swiss Forestry Project, discussed above, and the case study from Thailand below both illustrate how CBFM initiatives can adopt a more integrated approach to poverty reduction and the importance of understanding the livelihoods and assets of communities in a holistic way. 


\section{Managing mangroves to improve community livelihoods in Thailand}

This discussion draws on a case study prepared by Somying Soontornwong (2006). Pred Nai village in eastern Thailand is a socially heterogeneous community, with groups that have differing resources and power. The Pred Nai area was left with large areas of degraded mangrove forests after a boom and bust cycle of shrimp aquaculture and charcoal production. Since 1986, the Pred Nai Mangrove Conservation Group has worked to rehabilitate a 4800 hectare area of mangroves with some facilitation support from RECOFTC. The improvement of community livelihoods and integrated management of mangrove and marine resources were interwoven with the objective of mangrove rehabilitation.

Initially, RECOFTC stationed staff with different families in the village to gain a better understanding of the community situation, which highlighted the community's dependence on a wide web of activities and resources, including rice farming, harvesting of crabs, fish and shellfish, as well as mangrove forest products, such as poles for pepper trees. Key issues affecting the well-being of households were identified through this process as well as through participatory analysis with the villagers. The project then worked to improve the productivity of the mangrove system and its aquatic resources by developing a management regime, for instance the management of crab harvest around reproductive season. The project facilitated the formation of a crab bank group, which had a strong role in crab management and largely comprised the landless who lacked fishing equipment (i.e. were categorized in the community as poor), a Mangrove Herbal Production Group, which targets poor women, and a village savings group.

Recent studies have found that the mangrove forests have been effectively regenerated, as well as improving the abundance of and income from key aquatic resources such as crabs. Nevertheless, according to Soontornwong, it has been challenging to engage the poor in 'active' rather than "passive" participation.

The case highlights that looking at livelihoods and poverty in an integrated way can strengthen impacts on both poverty and resource management. The wider benefits of protecting a mangrove area, in its linkage with harvest of aquatic resources, are perhaps more obvious in a wetland context, but equally relevant to consider in other ecosystems. Similarly, in the case discussed earlier from Lao PDR, the bamboo harvesting initiative worked first to address a livelihood concern that was crucial to the village - rice shortage - through the establishment of a rice bank. A focus on poverty reduction thus invites CBFM practitioners to understand the various dimensions of poverty, and to look at beyond forests to see livelihoods in a wider context.

\section{Understanding processes of marginalisation in the Karnataka Watershed Development Project}

While not strictly a CBFM example, the Karnataka Watershed Development Project (KAWAD) provides an important insight into the importance of understanding the causes of poverty. The project was set up with UK government funding in 1998 in three watersheds of Karnataka, India, home to around 13,000 households (Wilkin et al., 2003). KAWAD aimed to improve the livelihoods of the population in addition to water and soil conservation, through activities such as village sanitation, small enterprise development and village credit schemes.

A mid-term review of the project in 2001 highlighted that the project was failing to reach the poorest households. Looking for ways to improve the situation, consultants helped the project staff to analyze the processes leading to the marginalization of groups such as the elderly, physically and mentally challenged, illiterates, devadasis 5 , single, widowed or deserted women, the landless, marginal farmers, unemployed farmers that are not self-employed, those dependent on a single occupation, socially alienated people and geographically isolated people. The stories of these groups were

\footnotetext{
${ }^{5}$ Devadasis are women who are forcibly dedicated to a deity from an early age and are unable to marry; some are drawn into prostitution through economic necessity.
} 
analyzed and compiled (see Wilkin et al., 2003).

By analyzing poverty in terms of marginalization processes, KAWAD was able to find entry points for intervention; a strategy for reaching these groups was then developed (Wilkin et al., 2003). For CBFM practitioners, a similar emphasis on analysing marginalization processes and gaining a detailed understanding of marginalized groups can help to understand who comprise 'the marginalized' in a given locality and to find entry points for working with these groups. Without this, we are left to work with assumptions about the causes of poverty, and CBFM programs that may be less effective in reaching these groups to improve their circumstances.

\section{CONCLUSION}

If, as we suggest, poverty is seen in a multidimensional way, the task of reducing poverty requires $\mathrm{CBFM}$ practitioners to think in new ways about the role of CBFM in poverty reduction. Some critical approaches in pro-poor CBFM identified here include:

- Gaining a better understanding of who is marginalized, the causes of poverty in specific localities, and the role of forest resources in this context;

- Improving opportunities for the poor to maximize their income from forest resources;

- $\quad$ Addressing governance to strengthen the resource rights and access of the poor, as well as benefit sharing from the use and marketing of resources; and

- Seeing CBFM in context, so that forest-based livelihoods are not

\section{REFERENCES}

Arnold, J.E.M. 2001. Forestry, Poverty and Aid. CIFOR Occasional Paper No. 33. Bogor, Indonesia: CIFOR.

Bass, S.; H. Reid; D. Satterthaite \& P. Steele. 2005. Conclusions. In S. Bass, H. Reid, D. Satterthaite and P. Steele. (Eds.), Reducing Poverty and Sustaining the Environment: The Politics of Local Engagement (pp. 280-310). London: Earthscan.

Bacalla, D.T. 2006. Equity: A Challenge in the Implementation of Community-Based Forest Management Strategy in the Philippines. In: S. Mahanty, J. Fox, M. Nurse, P. Stephen and L. McLees. (Eds.), Hanging in the Balance: Equity in Community Based Natural Resource Management in Asia treated in isolation from other assets and livelihood activities.

The cases presented in this paper highlight that progress is possible, but also that we still have far to go. Strategic opportunities have been highlighted in the paper. By pursuing a mix of approaches to address poverty and broader governance issues (targeting existing power structures), the opportunity will be there to scale up the poverty reduction potential of CBFM. Success will depend upon fostering a propoor orientation amongst service providers (government and non-government), and developing our skills and knowledge as practitioners in pro-poor approaches.

It is also important to recognize that CBFM can ultimately only make a partial contribution to poverty reduction (Fisher et al., 2005), but this contribution may be significant, in particular for communities with few alternative pathways out of poverty.

(pp. 162-181). Bangkok: RECOFTC and East-West Center.

Beck, T. \& Nesmith, C. 2001. Building on Poor People's Capacities: The Case of Common Property Resources in India and West Africa. World Development, 29(1): 119133.

Bhattacharya, B. 2006. Widening the Gap Between Terai and Hill Farmers in Nepal: the Implications of the New Forest Policy 2000. In S. Mahanty, J. Fox, M. Nurse, P. Stephen and L. McLees. (Eds.), Hanging in the Balance: Equity in Community Based Natural Resource Management in Asia (pp. 143-161). Bangkok: RECOFTC and EastWest Center. 
Brocklesby, M.A. 2004. Planning Against Risk: Tools for Analysing Vulnerability in Remote Rural Areas. Chars Organisational Learning Paper 2. London: DFID.

Carney, D. 1999. Approaches to Sustainable Livelihoods for the Rural Poor. Overseas Development Institute (ODI) Briefing.

Dewi, S.; Belcher B. \& Puntodewo, A. 2005. Village Economic Opportunities, Forest Dependence and Rural Livelihoods in East Kalimantan, Indonesia. World Development, 33(9): 1419-1434.

Fisher, R.J.; Maginnis, S.; Jackson, W.J.; Barrow, E. \& Jeanrenaud, S. 2005. Poverty and Conservation: Landscapes, People and Power. Gland, Switzerland: IUCN.

Gilmour, D.; Malla Y. \& Nurse M. 2004. Linkages Between Community Forestry and Poverty. Bangkok: RECOFTC.

Hobley, M. 2005. Where in the World is There Pro-Poor Forest Policy and Tenure Reform? Draft Report for Comment Prepared for The World Bank.

Loughhead, S.; Mittal, O. \& Wood, G. 2000. Urban Poverty and Vulnerability in India: Experience from a Social Perspective. Unpublished Paper Prepared for DFID, India.

Morris, J.; E. Hicks; A. Ingles \& S. Kethphanh. 2004. Linking Poverty Reduction with Forest Conservation: Case Studies from Lao PDR. Bangkok: IUCN.

National Agriculture and Forestry Research Institute; National Agriculture and Forestry Extension Service \& the National University of Lao PDR. 2005. Improving Livelihoods in the Upland of the Lao PDR. Volume 1: Initiatives and Approaches. NAFRI, Vientiane, Lao PDR.

Nurse, M.; Robinson P.; Paudel D. \& Pokharel, B.K. 2004. Towards Pro-poor Community Forestry - Recent Experiences from Dolakha and Okhaldhunga Districts. In N.P. Timsina and H.R. Ojha (Eds.), Case Studies on Equity and Poverty in the Management of Common Property Resources in Nepal. Kathmandu: ForestAction.

Paude1, D. 2005. Including the Excluded: A Pro-Poor Bel Fruit Juice Making Enterprise in Nepal. Report Prepared for the Regional Community Forestry Training Centre for
Asia and the Pacific (RECOFTC) and Forest Trends. Bangkok: RECOFTC.

Poteete, A. 2004. Is Decentralization a Reliable Means of Increasing Equity? Paper Prepared for the Tenth Biennial Conference of the International Association for the Study of Common Property (IASCP). Mexico, Oaxaca.

Sarin, M.; Singh, N.M.; Sundar N. \& Bhogal, R.K. 2003. Devolution as a Threat to Democratic Decision-making in Forestry? Findings from Three States in India. Working Paper 197. London: Overseas Development Institute.

San, S.L. 2006. Indicating Success: Evaluation of Community Protected Areas in Cambodia. In S.Mahanty, J. Fox, M. Nurse, P. Stephen and L. McLees. (Eds.), Hanging in the Balance: Equity in Community Based Natural Resource Management in Asia (pp. 14-27). Bangkok: RECOFTC and East-West Center.

Scherr, S.J.; White, A. \& Kaimowitz, D. 2004. A New Agenda for Forest Conservation and Poverty Reduction: Making Markets Work for Low-Income Producers. Washington DC: Forest Trends.

Soontornwong, S. 2006. Improving Livelihood through CBNRM: A Case Study of Self-organization in Community Mangrove Management in Thailand. In S. Mahanty, J. Fox, M. Nurse, P. Stephen and L. McLees. (Eds.), Hanging in the Balance: Equity in Community Based Natural Resource Management in Asia (pp. 182-199). Bangkok: RECOFTC and East-West Center.

Sunderlin, W.D.; Angelsen, A.; Belcher, B.; Burgers, P.; Nasi, R.; Santoso, L. \& Wunder, S. 2005. Livelihoods, Forests and Conservation in Developing Countries: An Overview. World Development, 33(9): 13831402.

World Bank. 2002: World Development Report 2000/2001: Attacking Poverty. New York: Oxford University Press.

United Nations Development Program; United Nations Environment Program; The World Bank and World Resources Institute. 2003. World Resources 20022004: Decisions for the Earth - Balance, Voice and Power. Washington DC: WRI. 
Walker, A. 2004. Seeing Farmers for the Trees: Community Forestry and the Arborealisation of Agriculture in Northern Thailand. Asia Pacific Viewpoint, 45(3): 311324.

Wilkin, K.; Mundayat, M. \& Gopinath, U. 2003. Karnataka Watershed Development Project: Voices in the Dark - Case Studies on Marginalisation. KAWAD Report No. 27. New Delhi, India: KAWAD Society.

Wood G. \& Salway, S. 2000. Introduction:
Securing Livelihoods in the Dhaka Slums. Journal of International Development, 12: 669-688.

World Resources Institute; United National Development Program; United Nations Environment Program and The World Bank. 2005. World Resources 2005: The Wealth of the Poor - Managing Ecosystems to Fight Poverty. Washington DC: WRI. 